\title{
Association of Genetic Polymorphisms in Genes Involved at the Branch Point of Nucleotide Biosynthesis and Remethylation with Down Syndrome Birth Risk: A Case-Control Study
}

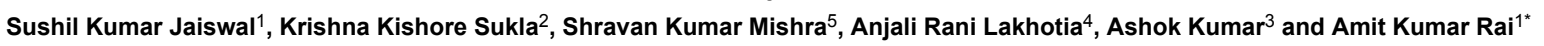

${ }^{1}$ Centre for Genetic Disorders, Banaras Hindu University, Varanasi, Uttar Pradesh, India

${ }^{2}$ Cytogenetics Laboratory, Department of Zoology, Banaras Hindu University, Varanasi, Uttar Pradesh, India

${ }^{3}$ Department of Pediatrics, Banaras Hindu University, Varanasi, Uttar Pradesh, India

${ }^{4}$ Department of Gynecology, Institute of Medical Sciences, Banaras Hindu University, Varanasi, Uttar Pradesh, India

${ }^{5}$ Department of Biotechnology, Veer Bahadur Singh Poorvanchal University, Jaunpur, Uttar Pradesh, India

*Corresponding author: Amit Rai, Centre for Genetic Disorders, Banaras Hindu University, Varanasi, Uttar Pradesh, India, Tel: 09670428502; E-mail: akrai10@gmail.com

Received date: December 21, 2015; Accepted date: April 05, 2016; Published date: April 10, 2016

Copyright: @ 2016 Jaiswal SK, et al. This is an open-access article distributed under the terms of the Creative Commons Attribution License, which permits unrestricted use, distribution, and reproduction in any medium, provided the original author and source are credited.

\begin{abstract}
DNA methylation and nucleic acid biosynthesis are two crucial phenomena for normal chromosomes segregation. From our earlier studies, MTHFR 677T individually and in combination with other gene polymorphisms, micronutrient deficiency, hyperhomocysteinemia was shown to be associated with risk in Down syndrome (DS) mothers. Remethylation and nucleic acid biosynthesis pathways are dependent on the activity of Methylenetetrahydrofolate reductase (MTHFR) and Thymidylate synthase (TYMS) respectively, competing for common substrate molecule 5,10-methelenetetrahydrofolate (5,10-MTHF). The role of MTHFD1 1958 G>A (affecting synthesis of 5,10-MTHF), MTHFR 677 C>T (affecting methylation), TYMS 5'UTR 28 bp repeat polymorphism and TYMS 3'UTR 6bp deletion polymorphism (affecting nucleic acid biosynthesis) in a cohort of 200 case mothers and 187 control mothers (also 146 case triads: mother, father, and child) were studied in the present study. We observed a significant association of MTHFR $677 \mathrm{C}>$ T in a co-dominant model $(p=0.0428)$ and dominant model $(0.0194)$ as well as TYMS 5'UTR $28 \mathrm{bp}$ repeat polymorphism in a recessive model $(p=0.0005)$ and dominant model $(0.0161)$. The genotypic combination analysis revealed a significant additive effect of certain genotypic combinations (especially combination of MTHFR 677 T and TYMS $2 \mathrm{R}$ alleles with other alleles or genotypes) in increasing risk. Weak linkage disequilibrium (LD) was observed between TYMS 5' and 3' UTR regions polymorphism in LD analysis. Transmission disequilibrium test (TDT) analysis revealed a consistent trend of preferential allele's transmission from parents. We concluded that genetic interaction of remethylation pathway and the nucleic acid metabolic pathway was significantly associated with risk factors for DS childbirth. However, replication studies are required to validate our observation in the population.
\end{abstract}

Keywords: Down syndrome; MTHFD1; MTHFR; TYMS; Folate; Homocysteine

\section{Introduction}

Chromosomal basis of Down syndrome (DS) due to abnormal segregation of chromosome 21 has been known for many years. The mechanism behind mal-segregation of the chromosome is still unknown. In $90 \%$ of the cases, the nondisjunction occurs during maternal meiosis 1 . Advanced maternal age during conception and reduced recombination are the only well-established known associated factors for mal-segregation of chromosome 21 [1]. James et al. hypothesized that maternal genetic polymorphism (MTHFR 677T) may cause hypomethylation in the pericentromeric region of the chromosome, thereby leading to nondisjunction of chromosome 21 and further predicted that impaired folate metabolism might act as a maternal risk factor for having a DS child [2].

However, several comparable studies done on populations from different regions of the world have yielded conflicting results; in developing countries, MTHFR 677T was a significant genetic predisposing factor, while in studies from Europe and the Americas it was not an associated risk factor [3]. Similarly, studies on other folatehomocysteine pathway genes [4-6] have shown a much heterogeneity, like that of MTHFR 677T in association with Down syndrome.

Folate metabolic pathway is involved in two essential physiological processes: nucleic acid biosynthesis and DNA repair; and remethylation of homocysteine to form methionine. Methylenetetrahydrofolate dehydrogenase (MTHFD1) is a trifunctional gene having methylene tetrahydrofolate dehydrogenase, methenyltetrahydrofolate cyclohydrolase and formyl tetrahydrofolate synthetase activity and is involved in interconversion of intermediates molecules tetrahydrofolates for consistently providing 5,10methlenetetrahydrofolate. It mediates the interconversion of 5,10MTHF, 5,10-methenylTHF, and 10-formylTHF. The last two are donor cofactors for denovo purine and pyrimidine biosynthesis [7].

Also, one MTHFD1 gene function utilizes MTHF as substrate and competes with MTHFR gene function for the same substrate. Further, Thymidylate synthase (TYMS) competes with MTHFR for 5, 10MTHF as a substrate. The former is involved in the conversion of dUMP to dTMP thus involved in nucleic acid biosynthesis, replication and repair and later is for remethylation of homocysteine to 
Citation: Jaiswal SK, Sukla KK, Mishra SK, Lakhotia AR, Kumar A, et al. (2016) Association of Genetic Polymorphisms in Genes Involved at the Branch Point of Nucleotide Biosynthesis and Remethylation with Down Syndrome Birth Risk: A Case-Control Study. J Mol Genet Med 10: 207. doi:10.4172/1747-0862.1000207

Page 2 of 9

methionine to form S-adenosylmethionine (Universal methyl donor). Therefore, polymorphism affecting the activity of one of these two enzymes may shift pool of 5,10-MTHF towards either DNA synthesis or DNA methylation in the pathway. Studies also have shown that the decrease in activity of TYMS due to genetic polymorphism may be responsible for the inadequate formation of pyrimidine dTTP. This, in turn, will result in impaired nucleic acid biosynthesis, DNA replication, DNA repair and finally leading to chromosomal strand break and damage. Micronuclei formation, a marker for chromosomal damage has been shown significantly higher in younger mothers of DS children [8].

An earlier study on eastern Indian cohort has shown that the mothers having the MTHFR 677T allele (especially TT homozygotes) were susceptible to having DS children [9]. In a recent study on eastern Indian population, a significant increased DNMT3B -579G/-149T allele frequency was observed in DS case mothers indicating an association of altered DNA methylation as a risk for DS [10].

Similarly, in a very recent study on Eastern Indian Cohort (on seven genetic polymorphisms SLC19A1 or RFC1 G80A, MTHFR C677T and A1298C, MTR A2756G, MTRR A66G, TCN2 C776G and CBS 844 in $68 \mathrm{bp}$ ) we have shown that MTHFR 677T is an associated genetic risk factor and gene-gene interactions have a significant role in genetic predisposition in DS mothers [11]. Hyperhomocysteinemia (hypHcy), vitamin-B12 and folate deficiency was significantly higher in the studied cohort of DS mothers. We have also shown from our previous findings that the incidence of hypHcy (30\%), Vitamin B12 (50\%) and folic acid $(11 \%)$ deficiency in a healthy population of eastern Indian populace [12]

The impaired Folate-Hcy pathway as an associated risk in DS mothers from our previous and recent findings led us to investigate the role of four polymorphisms (MTHFD1 G1958A, MTHFR C677T, TYMS 5'UTR 28bp repeats and TYMS 3'UTR 6bpdel) in the predisposition of mothers for DS childbirth. MTHFR 677T and TYMS 5 'UTR $2 R / 2 R$ independently and in combination with other genetic polymorphisms was significantly associated with risk in DS mothers.

\section{Materials and Methods}

\section{Subjects}

The cases were referred to the Centre for Genetic Disorders (Genetic diagnostic unit) for karyotyping, upon clinical examination in the Pediatrics Department of the Institute of Medical Sciences, Banaras Hindu University. The period of sample recruitment was from 2010 to 2014. A cohort of 200 mothers of a Down syndrome child (MDS) confirmed by karyotyping (includes 146 DS triads) and 187 control mothers were included in the study. The mean age of the MDS was $27.0 \pm 4.6$ years at the time of the DS childbirth while the age of MDS at the time of sample collection was little less than 28.5 years.

The age of control mothers was $26.0 \pm 4.2$ years at the time of the child birth. They were collected immediately after delivery. The age of the 146 DS children and fathers included in the study was found to be $11.5 \pm 3.5$ months and $32.5 \pm 4.2$ years, respectively. The socioeconomic status of both the case and control mothers was similar. Both groups belong to a low economical status. All patients belonged to Eastern Uttar Pradesh and the contiguous regions of Bihar, Jharkhand and Chhattisgarh. A peripheral blood sample was drawn from mother father, and child after obtaining a written consent from the parents.
Control mothers were recruited from the Outpatient clinic of the Gynecology Department, Banaras Hindu University, Varanasi, India.

We paid extreme caution during sampling from control mothers who had as a minimum of one healthy child and no history of any spontaneous abortions. Mothers having children with any chromosomal and/or congenital disorders were not included in the study as controls. This study was approved by the Institutional Ethical Committee of the Institute of Medical Sciences, Banaras Hindu University, Varanasi, India.

\section{DNA extraction}

A peripheral blood samples $(5 \mathrm{ml})$ was drawn from DS children, their parents, and control mothers under aseptic condition and in a heparinized syringe. Within a week of sample collection genomic DNA was extracted from the peripheral blood by high salt method, as described previously [13].

\section{Genotyping}

Genotyping for all the polymorphisms were performed using a polymerase chain reaction-restriction fragment length polymorphism method using gene specific primers $[9,14,15]$. The PCR product and restriction digested products were electrophoresed on agarose gel.

\section{Statistical analysis}

Allelic frequencies of the SNPs examined were tested for Hardy \& Weinberg equilibrium using a Chi-square test. The genetic risk among case and control groups was compared and tested by calculating odds ratio with a $95 \%$ class interval. A two-tailed p-value of $<0.05$ was interpreted as statistically significant (using Graphpad software). For the transmission disequilibrium test, we calculated the Chi-square value with one degree of freedom and a p-value $<0.05$ was taken to be significant.

Haplotype frequencies and linkage disequilibrium (LD) were calculated using the Haploview software (Version 4.2) developed at The Broad Institute (http://www.broadinstitute.org/), which is based on the EM algorithm. The standardized disequilibrium coefficient (D) and correlation coefficient $(\mathrm{r} 2)$ between these SNPs were calculated to investigate whether certain allelic combinations of the polymorphisms examined altered the genetic risk in MDS.

\section{Results}

\section{Univariate analysis}

MTHFD1 G1958A polymorphism: MTHFD1 G1958A genotype and allele frequency distribution in mothers of DS child and control mothers are shown in Table 1. We didn't observe any significantly altered distribution of alleles and genotype among case and control mothers in all the three applied models: recessive $(p=0.97)$, codominant (0.43) and dominant models ( $\mathrm{p}=0.53$ ).

MTHFR C677T polymorphism: Significant difference in distribution of MTHFR 677T allele was observed between case mothers $(0.21)$ and control mothers (0.14) with odds ratio $1.65(95 \%$ CI: $1.13-2.41 ; p=0.0125)$. The SNP was found to be associated with increased risk in both models co-dominant (odds ratio $1.61,95 \% \mathrm{CI}$ : 1.04-2.48; $\mathrm{p}=0.0428$ ) as well as in dominant (odds ratio 1.705, 95\% CI: $1.11-2.62 ; \mathrm{p}=0.0194)$. In recessive model, no significant association 
Citation: Jaiswal SK, Sukla KK, Mishra SK, Lakhotia AR, Kumar A, et al. (2016) Association of Genetic Polymorphisms in Genes Involved at the Branch Point of Nucleotide Biosynthesis and Remethylation with Down Syndrome Birth Risk: A Case-Control Study. J Mol Genet Med 10: 207. doi:10.4172/1747-0862.1000207

Page 3 of 9

with DS risk was obtained. The odds ratio for recessive model was found to be 5.75 with $95 \%$ CI to be $0.69-48.27$ and the p-value was 0.15 .

TYMS 5'UTR 28 bp repeats (2R/3R) polymorphism: TYMS 5'UTR 28 bp repeats $(2 \mathrm{R} / 3 \mathrm{R})$ polymorphism was found to be most significantly associated to increase risk in present study. Minor allele $(2 \mathrm{R})$ frequency was significantly higher in case mothers $(0.48)$ compared to control mothers (0.35) with odds ratio 1.72 (95\% CI: 1.28-2.29; $p=0.0003$ ). TYMS $2 \mathrm{R} 2 \mathrm{R}$ genotype was significantly higher in the case of mothers compared to control mothers with odds ratio 3.37 (95\% CI: 1.79-6.34; $\mathrm{p}=0.0002$ ). Recessive model, as well as dominant models of association, revealed significant association to increase risk with odds ratio 2.79 (95\% CI: $1.57-4.96 ; \mathrm{p}=0.0005)$ and $1.18(95 \% \mathrm{CI}$ : $1.12-2.62 ; \mathrm{p}=0.0161)$ respectively.

TYMS 3'UTR 6 bp deletion polymorphism: TYMS 3'UTR 6 bp deletion polymorphism didn't reveal association either in allele frequency distribution or in genotypic distribution among case and control mothers. All the model of association remained statistically insignificant among case and control mothers for this polymorphism. Minor allele (6bpdel) frequency distribution was almost same among case mothers (0.410) and control mothers (0.406).

\section{Bivariate analysis}

Genotypic combination: Following univariate analysis, we did genetic combination analysis of TYMS 5'UTR 28 bp repeats polymorphism (showing most significant association) with other studied polymorphism. In combination with MTHFD1 G1958A, the only combination TYMS 2R2R/MTHFD1 1958GA showed an additive effect of increasing risk in the case mothers compared to control mothers. Genotypic combinations of TYMS 5'UTR 28 bp repeats polymorphism with MTHFR C677T like 3R3R/CT, 3R2R/CT, $3 \mathrm{R} 2 \mathrm{R} / \mathrm{TT}, 2 \mathrm{R} 2 \mathrm{R} / \mathrm{CC}$ and 2R2R/CT were significantly higher in the case mothers compared to control mothers (Table 2). In case of genetic interaction of TYMS 5'UTR 28 bp repeats $(2 \mathrm{R} / 3 \mathrm{R})$ with TYMS 3 'UTR $6 \mathrm{bp}$ del polymorphism, the genotypic combinations 3R3R/ 6bp0-6bpdel, 3R2R/6bp0-6bp0, 3R2R/6bp0-6bpdel, 2R2R/6bp0-6bp0, and $2 \mathrm{R} 2 \mathrm{R} / 6 \mathrm{bp} 0-6 \mathrm{bpdel}$ were turned out significantly higher in the case mothers compared to control mothers.
Multivariate analysis: When case and control mothers were stratified and compared in terms of the number of variant alleles harbored, we found the incidence of more than four variant alleles was significantly higher in case mothers compared to control mothers with an odds ratio 6.52 (95\% CI: 2.17 - 19.61; p=0.008) (Table 3).

\section{Linkage dis-equilibrium (LD) analysis}

We performed linkage dis-equilibrium (LD) analysis for the two polymorphisms in TYMS gene. D' value was 0.288 with a LOD of 3.89 and an $\mathrm{r} 2$ value of 0.041 indicating weak linkage disequilibrium between the two polymorphisms. TYMS 5'UTR 28 bp repeat 2RTYMS 3'UTR $6 \mathrm{bp} 0$ haplotype was significantly higher in case mothers (0.343) compared to control mothers (0.246) with p-value 0.0031 . On the other side, $3 \mathrm{R}-6 \mathrm{bp} 0$ haplotype was significantly higher in control mothers $(0.347)$ compared to case mothers $(0.244)$ with a p-value of 0.0016 (Table 4).

\section{Transmission dis-equilibrium test (TDT) analysis}

TDT analysis was performed in a total of 146 DS trios families, included in the study to see the preferential transmission of alleles from either of the heterozygous parents to DS children (Table 5).

Although not statistically significant, we observed a consistent trend for preferential transmission of alleles to DS children. In case of paternal allele transmission, wild-type alleles TYMS 5'UTR 3R and TYMS 3'UTR 6bp0 (except MTHFD1 1958G) were transmitted more compared to respective risk allele, whereas in case of maternal alleles transmission, risk alleles TYMS 5'UTR 2R, MTHFD1 1958A (except TYMS 3'UTR 6bpdel) were preferentially transmitted to DS children, but this preferential transmission was statistically not significant from both the parents. When we evaluated the total transmitted alleles we found a borderline significant transmission of A allele of MTHFD1 polymorphism and $3 \mathrm{R}$ allele of TYMS $28 \mathrm{bp}$ tandem repeat polymorphism. We also found a very significant transmission of wild allele of TYMS 3'UTR 6 bp deletion polymorphism in children (Table $5)$.

\begin{tabular}{|c|c|c|c|c|c|}
\hline Gene and SNP & Genotype & $\begin{array}{l}\text { Case (\%) } \\
\mathrm{N}=200\end{array}$ & $\begin{array}{l}\text { Control (\%) } \\
\mathrm{N}=187\end{array}$ & $\mathrm{OR}(95 \% \mathrm{Cl})$ & $p$ value \\
\hline \multirow{6}{*}{$\begin{array}{l}\text { MTHFD1 G1958A } \\
\text { (rs2236225) }\end{array}$} & GG & $25(12.80)$ & $30(16.04)$ & 1.00 & Referent \\
\hline & GA & 104(53.30) & $94(50.27)$ & $1.33(0.73-2.42)$ & 0.4380 \\
\hline & AA & $66(33.90)$ & 63(33.69) & $1.457(0.67-2.37)$ & 0.5837 \\
\hline & Recessive model & - & - & $1.01(0.66-1.54)$ & 0.9742 \\
\hline & Dominant model & - & - & $1.25(0.71-2.23)$ & 0.5310 \\
\hline & A allele frequency & 0.40 & 0.41 & $1.07(0.80-1.43)$ & 0.6876 \\
\hline \multirow[t]{4}{*}{ MTHFR C677T (rs1801133) } & CC & 122(61) & $136(72.73)$ & 1.00 & Referent \\
\hline & CT & $72(36)$ & $50(26.74)$ & $1.61(1.04-2.48)$ & 0.0428 \\
\hline & TT & $6(3)$ & $1(0.53)$ & $6.69(0.80-56.37)$ & 0.1043 \\
\hline & Recessive model & - & - & $5.753(0.69-48.27)$ & 0.1508 \\
\hline
\end{tabular}


Citation: Jaiswal SK, Sukla KK, Mishra SK, Lakhotia AR, Kumar A, et al. (2016) Association of Genetic Polymorphisms in Genes Involved at the Branch Point of Nucleotide Biosynthesis and Remethylation with Down Syndrome Birth Risk: A Case-Control Study. J Mol Genet Med 10: 207. doi:10.4172/1747-0862.1000207

Page 4 of 9

\begin{tabular}{|c|c|c|c|c|c|}
\hline & Dominant model & - & - & $1.705(1.11-2.62)$ & 0.0194 \\
\hline & $T$ allele frequency & 0.21 & 0.14 & $1.65(1.127-2.405)$ & $0.0125^{*}$ \\
\hline \multirow{6}{*}{$\begin{array}{l}\text { TYMS 5' UTR } 28 \text { bp tandem repeats } \\
\text { (rs 45445694) }\end{array}$} & $3 R 3 R$ & $57(28.5)$ & $76(40.64)$ & 1.00 & Referent \\
\hline & 3R2R & $95(47.5)$ & $92(49.2)$ & $1.38(0.88-2.15)$ & 0.1974 \\
\hline & $2 \mathrm{R} 2 \mathrm{R}$ & $48(24)$ & $19(10.16)$ & $3.37(1.79-6.34)$ & $0.0002^{*}$ \\
\hline & Recessive model & - & - & $2.79(1.57-4.96)$ & $0.0005^{*}$ \\
\hline & Dominant model & - & - & $1.18(1.12-2.62)$ & 0.0161 \\
\hline & $2 R$ frequency & 0.48 & 0.35 & $1.72(1.28-2.29)$ & $0.0003^{*}$ \\
\hline \multirow{6}{*}{$\begin{array}{l}\text { TYMS 3' UTR 6bp deletion } \\
\text { (rs16430) }\end{array}$} & 6bpo/6bp0 & $68(34)$ & $73(39.04)$ & 1.00 & Referent \\
\hline & 6bp0/6bpdel & $99(50)$ & $76(40.64)$ & $1.40(0.90-2.18)$ & 0.1726 \\
\hline & 6bpdel/6bpdel & $33(16.50)$ & $38(20.32)$ & $0.93(0.5264-1.65)$ & 0.9244 \\
\hline & Recessive model & - & - & $0.78(0.46-1.30)$ & 0.4014 \\
\hline & Dominant model & - & - & $1.24(0.82-1.88)$ & 0.3558 \\
\hline & 6bpdel allele frequency & 0.41 & 0.406 & $1.03(0.77-1.37)$ & 0.9213 \\
\hline
\end{tabular}

Table 1: Association of MTHFD1 G1958A, MTHFR C677T, TYMS 5’ UTR 28 bp tandem repeats and TYMS 3' UTR 6bp deletion at 1494 polymorphism and Down syndrome risk. ${ }^{\star} \mathrm{P}$-Value Significant after Bonferroni multiple correction test.

\begin{tabular}{|c|c|c|c|c|c|c|c|c|c|}
\hline $\begin{array}{l}\text { TYMS } \\
\text { 5'UTR } 28 \\
\text { bp } \\
\text { repeats } \\
\text { (2R/3R) I } \\
\text { MTHFR } \\
\text { C677T }\end{array}$ & 3R3R/CC & 3R3R/CT & 3R3R/TT & 3R2R/CC & 3R2R/CT & 3R2R/TT & 2R2R/CC & 2R2R/CT & 2R2R/TT \\
\hline $\begin{array}{l}\text { Case } \\
\text { mothers } \\
(200)\end{array}$ & 24 & 31 & 1 & 59 & 32 & 5 & 38 & 10 & 0 \\
\hline $\begin{array}{l}\text { Control } \\
\text { mothers } \\
(187)\end{array}$ & 47 & 26 & 1 & 72 & 22 & 0 & 17 & 2 & 0 \\
\hline $\begin{array}{l}\text { Odds } \\
\text { ratio } 95 \% \\
\text { Cl }\end{array}$ & Referent & $\begin{array}{l}2.24 \\
(1.14-4.78)\end{array}$ & $\begin{array}{l}1.20 \\
(0.12-32.72)\end{array}$ & $\begin{array}{l}1.61 \\
(0.88-2.93)\end{array}$ & $\begin{array}{l}2.85 \\
(1.37-5.93)\end{array}$ & $\begin{array}{l}21.33 \\
(1.13-402.2)\end{array}$ & $\begin{array}{l}4.38 \\
(2.06-9.31)\end{array}$ & $\begin{array}{l}9.79 \\
(1.98-48.32)\end{array}$ & - \\
\hline$P$ value & 1.0 & 0.0309 & 0.6340 & 0.1616 & 0.0080 & 0.0136 & 0.0002 & 0.0036 & - \\
\hline $\begin{array}{l}\text { TYMS } \\
\text { 5'UTR } 28 \\
\text { bp } \\
\text { repeats } \\
\text { (2R/3R) I } \\
\text { TYMS } \\
\text { 3'UTR } \\
\text { 6bp0/6bp } \\
\text { del }\end{array}$ & 3R3R/6bp-6bp & $\begin{array}{l}\text { 3R3R/ } \\
\text { 6bp-6bpdel }\end{array}$ & $\begin{array}{l}\text { 3R3R/ } \\
\text { 6bpdel-6bpdel }\end{array}$ & $\begin{array}{l}\text { 3R2R/ } \\
6 b p-6 b p\end{array}$ & $\begin{array}{l}\text { 3R2R/ } \\
\text { 6bp-6bpdel }\end{array}$ & $\begin{array}{l}\text { 3R2R/ } \\
\text { 6bpdel-6bpdel }\end{array}$ & $2 R 2 R / 6 b p-6 b p$ & $\begin{array}{l}\text { 2R2R/ } \\
\text { 6bp-6bpdel }\end{array}$ & $\begin{array}{l}\text { 2R2R/ } \\
\text { 6bpdel-6bpde } \\
\text { I }\end{array}$ \\
\hline $\begin{array}{l}\text { Case } \\
\text { mothers } \\
(200)\end{array}$ & 8 & 33 & 16 & 36 & 45 & 14 & 24 & 20 & 4 \\
\hline $\begin{array}{l}\text { Control } \\
\text { mothers } \\
(187)\end{array}$ & 25 & 27 & 21 & 39 & 40 & 15 & 9 & 8 & 3 \\
\hline
\end{tabular}


Citation: Jaiswal SK, Sukla KK, Mishra SK, Lakhotia AR, Kumar A, et al. (2016) Association of Genetic Polymorphisms in Genes Involved at the Branch Point of Nucleotide Biosynthesis and Remethylation with Down Syndrome Birth Risk: A Case-Control Study. J Mol Genet Med 10: 207. doi:10.4172/1747-0862.1000207

Page 5 of 9

\begin{tabular}{|c|c|c|c|c|c|c|c|c|c|}
\hline $\begin{array}{l}\text { Odds } \\
\text { ratio } 95 \% \\
\text { Cl }\end{array}$ & Referent & $\begin{array}{l}3.82 \\
(1.49-9.83)\end{array}$ & $\begin{array}{l}2.38 \\
(0.85-6.66)\end{array}$ & $\begin{array}{l}4.42 \\
(1.15-7.21)\end{array}$ & $\begin{array}{l}3.52 \\
(1.43-8.67)\end{array}$ & $\begin{array}{l}2.92 \\
(0.99-8.58)\end{array}$ & $\begin{array}{l}8.33 \\
(2.76-25.16)\end{array}$ & $\begin{array}{l}7.81 \\
(2.49-24.50)\end{array}$ & $\begin{array}{l}4.16 \\
(0.76-22.72)\end{array}$ \\
\hline$P$ value & 1.0 & 0.0083 & 0.1557 & 0.0355 & 0.0091 & 0.0877 & 0.0002 & 0.0006 & 0.2036 \\
\hline $\begin{array}{l}\text { TYMS } \\
\text { 5'UTR } 28 \\
\text { bp } \\
\text { repeats } \\
\text { (2R/3R)/ } \\
\text { MTHFD } \\
\text { G1958A }\end{array}$ & 3R3R/GG & 3R3R/GA & 3R3R/AA & 3R2R/GG & $3 R 2 R / G A$ & 3R2R/AA & 2R2R/GG & 2R2R/GA & 2R2R/AA \\
\hline $\begin{array}{l}\text { Case } \\
\text { mothers } \\
\text { (200) }\end{array}$ & 9 & 21 & 26 & 13 & 50 & 32 & 8 & 33 & 8 \\
\hline $\begin{array}{l}\text { Control } \\
\text { mothers } \\
\text { (187) }\end{array}$ & 11 & 34 & 29 & 17 & 51 & 26 & 2 & 9 & 8 \\
\hline $\begin{array}{l}\text { Odds } \\
\text { ratio } 95 \% \\
\mathrm{Cl}\end{array}$ & Referent & $\begin{array}{l}0.76 \\
(0.27-2.13)\end{array}$ & $\begin{array}{l}1.10 \\
(0.39-3.06)\end{array}$ & $\begin{array}{l}0.94 \\
(0.30-2.92)\end{array}$ & $\begin{array}{l}1.20 \\
(0.46-3.14)\end{array}$ & $\begin{array}{l}1.50 \\
(0.54-4.18)\end{array}$ & $\begin{array}{l}4.89 \\
(0.82-29.07)\end{array}$ & $\begin{array}{l}4.48 \\
(1.42-14.13)\end{array}$ & $\begin{array}{l}1.22 \\
(0.33-4.57)\end{array}$ \\
\hline$P$ value & 1.00 & 0.7899 & 0.8615 & 0.9074 & 0.9018 & 0.5989 & 0.1519 & 0.0186 & 0.7652 \\
\hline
\end{tabular}

Table 2: Genotypic combination of TYMS 5' UTR 28 bp repeat polymorphism with other polymorphism.

\begin{tabular}{|c|c|c|c|c|}
\hline Number of risk allele & $\begin{array}{l}\text { Case mothers (\%) } \\
\mathrm{N}=\mathbf{2 0 0}\end{array}$ & $\begin{array}{l}\text { Control mothers (\%) } \\
\mathrm{N}=187\end{array}$ & OR(95\% Cl) & $p$ value \\
\hline None/1 & $8(4)$ & $18(9.63)$ & Referent & 1.00 \\
\hline 2 & $33(16.5)$ & $41(21.93)$ & $1.81(0.70-4.68)$ & 0.26 \\
\hline 3 & $68(34)$ & $62(33.16)$ & $2.47(1.02-6.08)$ & 0.054 \\
\hline 4 & $62(31)$ & $56(29.95)$ & $2.49(1.01-6.17)$ & 0.052 \\
\hline$>4$ & $29(14.50)$ & $10(5.35)$ & $6.52(2.17-19.61)$ & 0.0008 \\
\hline$>2$ & $159(79.5)$ & $128(68.5)$ & $2.80(1.18-6.64)$ & 0.022 \\
\hline
\end{tabular}

Table 3: Incidence of risk genotypic presence among the case and controls mothers.

\begin{tabular}{|l|l|l|l|l|}
\hline $\begin{array}{l}\text { Haplotypes TYMS 5'UTR 28 bp } \\
\text { repeats } \begin{array}{l}\text { (2R/3R) and TYMS } \\
\text { 3'UTR 6bp0/6bpdel }\end{array}\end{array}$ & Total Frequency & $\begin{array}{l}\text { Case frequency } \\
\mathbf{N = 2 0 0}\end{array}$ & $\begin{array}{l}\text { Control frequency } \\
\mathbf{N}=187\end{array}$ & Chi square \\
\hline 2R-6bp0 & 0.297 & 0.343 & 0.246 & 8.725 \\
\hline 3R-6bp0 & 0.294 & 0.244 & 0.347 & 9.905 \\
\hline 3R-6bpdel & 0.288 & 0.276 & 0.300 & 0.54 \\
\hline 2R-6bpdel & 0.122 & 0.137 & 0.107 & 0.4622 \\
\hline
\end{tabular}

Table 4: Analysis of Haplotypes in MDS and control mothers.

\begin{tabular}{|l|l|l|l|}
\hline Genotype & Paternal alleles & Maternal alleles \\
\hline MTHFD1 G1958A & & Total alleles \\
\hline G & 23 & 29 & 107 \\
\hline
\end{tabular}


Citation: Jaiswal SK, Sukla KK, Mishra SK, Lakhotia AR, Kumar A, et al. (2016) Association of Genetic Polymorphisms in Genes Involved at the Branch Point of Nucleotide Biosynthesis and Remethylation with Down Syndrome Birth Risk: A Case-Control Study. J Mol Genet Med 10: 207. doi:10.4172/1747-0862.1000207

Page 6 of 9

\begin{tabular}{|l|l|l|l|}
\hline A & 24 & 30 & 133 \\
\hline X2 - Test & 0.021 & 0.017 & 2.86 \\
\hline P-value & 0.88 & 0.90 & 0.09 \\
\hline TYMS 5'UTR 28 bp tandem repeats & & & \\
\hline 3R & 29 & 19 & 120 \\
\hline 2R & 20 & 30 & 94 \\
\hline X2 - Test & 1.62 & 2.43 & 3.15 \\
\hline P-value & 0.20 & 0.12 & 0.07 \\
\hline TYMS 3'UTR 6 bp deletion & & & 145 \\
\hline 6bp & 33 & 34 & 93 \\
\hline 6bp deletion & 21 & 27 & 11.36 \\
\hline X2 - Test & 2.67 & 0.80 & 0.0008 \\
\hline P-value & 0.10 & 0.37 & \\
\hline
\end{tabular}

Table 5: Transmission disequilibrium test analysis (TDT).

\section{Discussion}

MTHFR C677T has been widely studied polymorphism in case of Down syndrome in different populations and in a recent meta-analysis it has been reported to be independent risk factor along with MTRR A66G and RFC1 G80A [16]. In the present study, MTHFR 677T allele (dominant model MTHFR CT+TT vs CC and co-dominant model MTHFR CT vs TT) was observed to be an associated risk factor and was in concordance with our previous findings $[9,11]$.

In the present study MTHFD1 G1958A polymorphism affecting availability of 5,10-methelene THF didn't turn out to be associated risk with respect to DS. There are conflicting results for association of MTHFD1 G1958A polymorphism with the risk of DS [17-20]. The combined genotype MTHFD1 1958 AA/RFC1 80GG has also been reported to be associated with risk for DS [21]. Similarly, in our study the combined genotype of MTHFD1 1958GA/TYMS 5'UTR 2R/2R was associated with increased risk in DS mothers (Table 2). Also, in a meta-analysis, the dominant model of MTHFD1 (GA vs. GG) has been reported to be an associated risk factor [22]. MTHFD1 gene polymorphism has been shown to be associated with increased risk in case of neural tube defects, congenital heart defect and unexplained second-trimester pregnancy loss [14,23,24].

In the present study, TYMS 5'UTR 28bp repeat polymorphism independently turned out to be associated risk factor in DS mothers. But TYMS 3'UTR region polymorphism didn't reveal any association with DS risk. TYMS and MTHFR genes have been suggested to affect drift of pool of 5,10-methyleneTHF either towards remethylation or nuleic acid biosynthesis pathway [25]. TYMS 5'UTR region 28bp repeats polymorphism is associated with gene expression [26] and 3'UTR 6bpdel polymorphism affect stability of m-RNA in cytoplasm [27] thus affecting formation of dTTP for nucleic acid biosynthesis. Apparently, interaction of genetic polymorphism of TYMS and MTHFR might be playing crucial role in chromosome damage and mal-segregation of the chromosome and thereby leading to nondisjunction of chromosome 21. The non-disjunction phenomenon occurs predominantly during meiosis I of embryonic development of DS mothers in grandmothers womb.

TYMS 3'UTR 6bpdel/6bpdel genotype has been reported to be associated with high level of red folate cell and lower homocysteine when compared with individual with TYMS 6bp/6bp genotype [28]. TYMS 6bpdel/6bpdel genotype has been shown associated with reduced risk of certain cancer $[15,29,30]$. It is associated with reduced risk for spina bifida in a study from Calfornia [31]. TYMS 6bpdel/6bp genotype has been reported to associate to have increased risk over TYMS 6bp/6bp in case of conotruncal heart defect in population of California [32]. In our case, TYMS 3'UTR 6bp/6bpdel polymorphism didn't turn out significantly associated with increased genetic risk in DS mothers.

We also looked into gene-gene interactions; the effect of TYMS 5'UTR 28bp repeats polymorphism in combination with MTHFR C677T, MTHFD1 G1958A and TYMS 3'UTR 6bp/6bpdel polymorphism was analyzed. TYMS 5'UTR $2 \mathrm{R}$ allele was found to be independent risk factor and it is obvious from Table 2 that, MTHFR 677T allele has additive effect. MTHFR 677CT was found to interact with all genotypes of TYMS 5'UTR polymorphism (even with 3R3R) and have been shown to be significantly associated with increased risk in DS mothers. The interaction of TYMS polymorphisms was not of significant scale with respect to mothers with MTHFR 677TT genotype due to a less sample size. Polymorphism in MTHFD1 G1958A was not found to have significant additive effect to TYMS 5'UTR 28bp repeats polymorphism except for one combination TYMS 2R2R/MTHFD1 GA. We observed additive effect of TYMS 3'UTR polymorphism with TYMS 5'UTR polymorphism. Further, weak linkage dis-equilibrium was observed for the two polymorphisms of TYMS in our case. Haplotypes TYMS 5'UTR 2R-TYMS 3'UTR 6bpdel and TYMS 5'UTR 3R- TYMS 3'UTR 6bp were significantly higher in case mothers and control mothers respectively in the present study. It is obvious from this interaction that TYMS 5'UTR $3 R$ allele and TYMS 3'UTR 6bp allele synergistically are protective in control mothers. Linkage disequilibrium has been reported for TYMS 3'UTR 6bpdel 
Citation: Jaiswal SK, Sukla KK, Mishra SK, Lakhotia AR, Kumar A, et al. (2016) Association of Genetic Polymorphisms in Genes Involved at the Branch Point of Nucleotide Biosynthesis and Remethylation with Down Syndrome Birth Risk: A Case-Control Study. J Mol Genet Med 10: 207. doi:10.4172/1747-0862.1000207

Page 7 of 9

allele and TYMS 5'UTR $3 \mathrm{R}$ allele $[33,34]$ but weak linkage diseulilibrium was reported for this haplotype revealing protective effect in another study by Zhu et al., [32]. To the best of our knowledge, there is only one study [8] so for available for association of these two polymorphisms in case of DS. MTHFR 1298AC/TYMS 2R/2R genotypic combination is associated with reduced risk factor for DS in Italian population [8]. In another study, the $2 \mathrm{R} / 2 \mathrm{R}$ genotype has been reported to be protective for coronary artery disease [35] and in drug response for certain cancer treatment $[27,36,37]$ via interaction with folate intake. Further in a study of Artificial neural network analysis by Coppede et al., revealed TYMS 2R/3R genotype is closely connected with a condition of being mothers of DS and TYMS 3R/3R genotype connected with control mothers [38]. TYMS 2R/2R genotype has been reported to increase risk of spina bifida in infants [31].

The present study also included 146 DS trios families; we performed transmission disequilibrium analysis to see preferential transmission of any allele from heterozygous parents. We didn't observe significant preferential transmission of any of the alleles in DS children from their heterozygous parents. Although not statistically significant, we observed consistent trend for preferential transmission of alleles to DS children. Wild-type alleles TYMS 5'UTR 3R, TYMS 3'UTR 6bp and mutant allele i.e., A allele of MTHFD1 G1958A polymorphism (risk allele) were transmitted more to DS children (Table 5). The MTHFD1 1958A genotype was shown to be decreasing the enzymatic efficiency thereby allowing the substrate to enter more nucleotide biosynthesis. Similarly both the wild alleles of the TYMS polymorphisms studied will promote nucleotide synthesis more promptly than mutant alleles. All these conditions favor nucleotide synthesis which is very crucial during embryonic development. By favoring nucleotide biosynthesis, we believe that preferential transmission of TYMS 3'UTR 6bp allele and border line preference of an allele of MTHFD1 G1958A, 3R allele of TYMS 5'UTR in DS children helps in selective advantage to the growing fetus. Further studies are required to validate our observations.

Deficiency of folate and Vit-B12 leading to impaired folate metabolism resulted into aberrant DNA methylation, chromosome breakage, increased frequency of micronuclei formation, defective chromosome recombination and aneuploidy has been already reported $[39,40]$. Association of genetic polymorphism of folate metabolism with genomic instability and mal-segregation chromosome has been reported in human blood cells [8,41-43]. Further, increased frequency of chromosome damage and mal-segregation of chromosome 13 and 21 have been reported in younger aged mothers compared to control mothers revealing that mothers of DS children have tendency of chromosomal damage and mal-segregation not only in germ lines but also in somatic cells [44]. In another study, Coppede 2009 showed correlation of increased frequency micronuclei formation with MTHFR C677T and MTHFR A1298C in lymphocytes of MDS [8]. In the same study, combined genotypes MTHFR 677TT/MTR 2756AA and MTHFR 1298AC/TYMS2R2R were associated as increased and decreased risk for DS respectively. In the present study, MTHFR C677T and TYMS 5'UTR 28bp repeat polymorphisms independently as well as in combination with each other are significantly associated with risk for DS. Interestingly, both the genes are dependent on the same substrate molecule 5,10-methlenetetrahydrofolate. From our earlier and recent work, we have demonstrated that gene-gene interactions (gene polymorphisms of folate-homocysteine) and micronutrient status (folate, and vitamin B12) independently and cumulatively are significantly associated risk factors in mothers for DS baby birth [9-11].
Coppede have shown that TYMS 5'UTR $2 \mathrm{R} / 2 \mathrm{R}$ acts as a protective genotype in control mothers and the logic put forward was that this genotype will allow a slight decrement in nucleotide biosynthesis and thereby promoting more remethylation reaction [8]. This, in turn, will allow proper DNA methylation at pericentromeric region and thereby preventing the nondisjunction. But in a population with folatehomocysteine impairment (like the present cohort), a condition of low micronutrient levels and/or genetic predisposition (MTHFR 677T and other gene polymorphisms), will lead to a limited synthesis of 5, 10methylenetetrahydrofolate. This will restrict the formation of 5methylenetetrahydrofolate for remethylation of homocysteine resulting into hyperhomocysteinemia and DNA hypomethylation. If the nucleotide biosynthesis is also hindered in such population, it might prove selective disadvantage for the growing fetus. This can be explained as follows, in $90 \%$ of DS cases, non-disjunction of chromosome 21 occurs at meiosis I of gametes formation in embryonic development stage of mothers. At this time, there is high requirement of nucleic acid biosynthesis for DNA replication and repair. Also, in developing fetus there is high need of nucleic acid biosynthesis as well as methylation for proper development of fetus.

In summary, we found significant association of TYMS 5'UTR 2R/2R and MTHFR C677T independently and in combination with increased risk of mothers predisposed to DS baby birth. Two other SNPs, TYMS 3' UTR 6bp del/6bp del and MTHFD1 G1958A were not associated as risk factor for DS, however in genetic combination with TYMS (5'UTR $2 \mathrm{R} / 2 \mathrm{R})$, certain combinations were acting as risk factor. We observed an epistatic interaction between genes involved nucleotide biosynthesis and remethylation and these interactions were significantly associated with genetic predisposition in DS mothers. Replication studies are necessary to confirm our results to elucidate the underlining mechanism.

\section{Acknowledgement}

We thank MDS and control mothers for participation in the study. We record words of gratitude to our teacher Professor Rajiva Raman for critical analysis and comments. We are thankful to Centre for Genetic Disorders, BHU for chromosomal analysis. This work forms part of the contribution of the Disease biology thrust area under DBT sponsored Interdisciplinary School of Life Sciences, BHU. Indian Council of Medical Research (ICMR), New Delhi, India is highly acknowledged for fellowship.

\section{Conflict of Interest}

The authors declare no conflict of interest.

\section{Authors Contribution}

Conceived and designed the experiments: S.K.J., K.K.S., A.K.R Performed the experiments: S.K.J. and S.K.M Analyzed the data: S.K.J., K.K.S., and A.K.R. Wrote the Manuscript: S.K.J., K.K.S., and A.K.R. Clinical samples provided by: A.K. and A.R.L. Collected the samples: S.K.J. Gave critical comments on the manuscript: A.K. and A.R.L.

\section{References}

1. Allen EG, Freeman SB, Druschel C, Hobbs CA, O'Leary LA, et al. (2009) Maternal age and risk for trisomy 21 assessed by the origin of chromosome nondisjunction: a report from the Atlanta and National Down Syndrome Projects. Hum Genet 125: 41-52. 
Citation: Jaiswal SK, Sukla KK, Mishra SK, Lakhotia AR, Kumar A, et al. (2016) Association of Genetic Polymorphisms in Genes Involved at the Branch Point of Nucleotide Biosynthesis and Remethylation with Down Syndrome Birth Risk: A Case-Control Study. J Mol Genet Med 10: 207. doi:10.4172/1747-0862.1000207

Page 8 of 9

2. James SJ, Pogribna M, Pogribny IP, Melnyk S, Hine RJ, et al. (1999) Abnormal folate metabolism and mutation in the methylenetetrahydrofolate reductase gene may be maternal risk factors for Down syndrome. Am J Clin Nutr 70: 495-501.

3. Wu X, Wang X, Chan Y, Jia S, Luo Y, et al. (2013) Folate metabolism gene polymorphisms MTHFR C677T and A1298C and risk for Down syndrome offspring: a meta-analysis. Eur J Obstet Gynecol Reprod Biol 167: 154-159.

4. Coppede` F, Bosco P, LorenzoniV, Migheli F, Barone C, et al. (2013a) The MTR 2756A $>$ G polymorphism and maternal risk of birth of a child with Down syndrome: a case-control study and a meta-analysis. Mol Bio Rep 40: 6913-6925.

5. Coppede ' F, Lorenzoni V, Migliore L (2013b) The reduced folate carrier (RFC-1) $80 \mathrm{~A}>\mathrm{G}$ polymorphism and maternal risk of having a child with Down syndrome: a meta-analysis. Nutrients 5: 2551-2563.

6. Coppede` F, Bosco P, Lorenzoni V, Denaro M, Anello G, et al. (2014) The MTRR 66A $>\mathrm{G}$ polymorphism and maternal risk of birth of a child with Down syndrome in Caucasian women: a case-control study and a metaanalysis. Mol Bio Rep 41: 5571-5583.

7. Hol FA, van der Put NM, Geurds MP, Heil SG, Trijbels FJ, et al. (1998) Molecular genetic analysis of the gene encoding the trifunctional enzyme MTHFD (methylenetetrahydrofolate dehydrogenase, methenyltetrahydrofolate cyclohydrolase, formyltetrahydrofolate synthetase) in patients with neural tube defects. Clin Genet 53: 119-125.

8. Coppedè F, Migheli F, Bargagna S, Siciliano G, Antonucci I, et al. (2009) Association of maternal polymorphisms in folate metabolizing genes with chromosome damage and risk of Down syndrome offspring. Neurosci Lett 449: 15-19.

9. Rai AK, Singh S, Mehta S, Kumar A, Pandey LK, et al. (2006) MTHFR C677T and A1298C are risk factors for Down syndrome in Indian mothers. J Hum Genet 51: 278-283.

10. Jaiswal SK, Sukla KK, Kumari N, Lakhotia AR, Kumar A, et al. (2015) Promoter polymorphisms of DNMT3B gene and risk for Down syndrome: A case-control study. Birth Defects Research (PART A) 103: 298-304.

11. Sukla KK, Jaiswal SK, Rai AK, Mishra OP, Gupta V, et al. (2015) Role of Folate- Homocysteine pathway gene polymorphisms and Nutritional cofactors in Down syndrome: A triad study. Hum Reprod 30: 1982-1993.

12. Sukla KK, Raman R (2012) Association of MTHFR and RFC1 gene polymorphism with hyperhomocysteinemia and its modulation by vitamin B12 and folic acid in an Indian population. Eur J Clin Nutr 66: 111-118.

13. Miller SA, Dykes DD, Polesky HF (1988) A simple salting out procedure for extracting DNA from human nucleated cells. Nucleic Acids Res 16: 1215.

14. Brody LC, Conley M, Cox C, Kirke PN, McKeever MP, et al. (2002) A polymorphism, R653Q, in the trifunctional enzyme methylenetetrahydrofolate dehydrogenase /methenyltetrahydrofolate cyclohydrolase/formyltetrahydrofolate synthetase is a maternal genetic risk factor for neural tube defects: report of the Birth Defects Research Group. Am J Hum Genet 71: 1207-1215.

15. Zhang Z, Shi Q, Sturgis EM, Spitz MR, Hong WK, et al. (2004) Thymidylate synthase 5'- and 3'- untranslated region polymorphisms associated with risk and progression of squamous cell carcinoma of the head and neck. Clin Cancer Res 10: 7903-7910.

16. Coppedè $\mathrm{F}$ (2015) The genetics of folate metabolism and maternal risk of birth of a child with Down syndrome and associated congenital heart defects. Front Genet 6: 223.

17. Zampieri BL, Biselli JM, Goloni-Bertollo EM, Pavarino EC (2012a) BHMT G742A and MTHFD1 G1958A polymorphisms and Down syndrome risk in the Brazilian population. Genet Test Mol Biomarkers 16: 628-631.

18. Zampieri BL, Biselli JM, Goloni-Bertollo EM, Vannucchi H, Carvalho VM, et al. (2012b) Maternal risk for Down syndrome is modulated by genes involved in folate metabolism. Dis Markers 32: 730-81.
19. Liao YP, Zhang D, Zhou W, Meng FM, Bao M S, et al. (2014) Combined folate gene MTHFD and TC polymorphisms as maternal risk factors for Down syndrome in China. Genet Mol Res 13: 1764-1773.

20. Izci Ay O, Ay ME, Erdal ME, Cayan F, Tekin S, et al. (2015) Folate metabolism gene polymorphisms and risk for Down syndrome offspring in Turkish women. Genet Test Mol Biomarkers 19: 191-197.

21. Scala I, Granese B, Sellitto M, Salomè S, Sammartino A, et al. (2006) Analysis of seven maternal polymorphisms of genes involved in homocysteine/folate metabolism and risk of Down syndrome offspring. Genet Med 8: 409-416.

22. Balduino Victorino D, deGodoy MF, Goloni-Bertollo EM Pavarino ÉC (2014) Genetic polymorphisms involved in folate metabolism and maternal risk for down syndrome: a meta-analysis. Dis Markers 2014: 517504.

23. Parle-McDermott A, Pangilinan F, Mills JL, Signore CC, Molloy AM, et al. (2005) A polymorphism in the MTHFD1 gene increases a mother's risk of having an unexplained second-trimester pregnancy loss. Mol Hum Reprod 11: 477-480.

24. Christensen KE, Rohlicek CV, Andelfinger GU, Michaud J, Bigras JL, et al. (2009) The MTHFD1 p.Arg653Gln variant alters enzyme function and increases risk for congenital heart defects. Hum Mutat 30: 212-220.

25. Trinh BN, Ong CN, Coetzee GA, Yu MC, Laird PW (2002) Thymidylate synthase: a novel genetic determinant of plasma homocysteine and folate levels. Hum Genet 111: 299-302.

26. Horie N, Aiba H, Oguro K, Hojo H, Takeishi K (1995) Functional analysis and DNA polymorphism of the tandemly repeated sequences in the 5_terminal regulatory region of the human gene for thymidylatesynthase. Cell Struct Funct 20: 191-197.

27. Ulrich CM, Bigler J, Bostick R, Fosdick L, Potter JD (2002) Thymidylate synthase promoter polymorphism, interaction with folate intake, and risk of colorectal adenomas. Cancer Res 62: 3361-3364.

28. Kealey C, Brown KS, Woodside JV, Young I, Murray L, et al. (2005) A common insertion/deletion polymorphism of the thymidylate synthase (TYMS) gene is a determinant of red blood cell folate and homocysteine concentrations. Hum Genet 116: 347-353.

29. Shi Q, Zhang Z, Neumann AS, Li G, Spitz MR, et al. (2005) Case-control analysis of thymidylate synthase polymorphisms and risk of lung cancer. Carcinogenesis 26: 649-656.

30. Skibola CF, Forrest MS, Coppede F, Agana L, Hubbard A, et al. (2004) Polymorphisms and haplotypes in folate-metabolizing genes and risk of non-Hodgkin lymphoma. Blood 104: 2155-2162.

31. Volcik KA, Shaw GM, Zhu H, Lammer EJ, Laurent C, et al. (2003) Associations between polymorphisms within the thymidylate synthase gene and spina bifida. Birth Defects Res A Clin Mol Teratol 67: 924-928.

32. Zhu H, Yang W, Shaw N, Perloff S, Carmichael SL, et al. (2012) Thymidylate Synthase (TYMS) polymorphisms and risk of conotruncal heart defects. Am J Med Genet A 9: 2194-2203.

33. Mandola MV, Stoehlmacher J, Zhang W, Groshen S, Yu MC, et al. (2004) A 6 bp polymorphism in the thymidylate synthase gene causes message instability and is associated with decreased intratumoral TS mRNA levels. Pharmacogenetics 14: 319-327.

34. Stoehlmacher J, Goekkurt E, Mogck U, Aust DE, Kramer M, et al. (2008) Thymidylate synthase genotypes and tumour regression in stage II/III rectal cancer patients after neoadjuvant fluorouracil-based chemoradiation. Cancer Lett 272: 221-225.

35. Vijaya Lakshmi SV, Naushad SM, Rupasree Y, Seshagiri Rao D, Kutala VK (2011) Interactions of 5'-UTR thymidylate synthase polymorphism with 677C $\rightarrow \mathrm{T}$ methylene tetrahydrofolate reductase and $66 \mathrm{~A} \quad->\mathrm{G}$ methyltetrahydrofolate homocysteine methyl-transferase reductase polymorphisms determine susceptibility to coronary artery disease. J Atheroscler Thromb 18: 56-64.

36. Pietrzyk JJ, Bik-Multanowski M, Skoczen S, Kowalczyk J, Balwierz W, et al. (2011) Polymorphism of the thymidylate synthase gene and risk of relapse in childhood ALL. Leuk Res 35: 1464-1466.

37. Uchida K, Hayashi K, Kawakami K, Schneider S, Yochim JM, et al. (2004) Loss of heterozygosity at the thymidylate synthase (TS) locus on 
Citation: Jaiswal SK, Sukla KK, Mishra SK, Lakhotia AR, Kumar A, et al. (2016) Association of Genetic Polymorphisms in Genes Involved at the Branch Point of Nucleotide Biosynthesis and Remethylation with Down Syndrome Birth Risk: A Case-Control Study. J Mol Genet Med 10: 207. doi:10.4172/1747-0862.1000207

Page 9 of 9

chromosome 18 affects tumor response and survival in individuals heterozygous for a 28-bp polymorphism in the TS gene. Clin Cancer Res. 10: 433-439.

38. Coppedè F, Grossi E, Migheli F, Migliore L (2010) Polymorphisms in folate metabolizing genes, chromosome damage, and risk of Down syndrome in Italian women: identification of key factors using artificial neural networks. BMC Med Genomics 3: 42.

39. Fenech M (2001) The role of folic acid and vitamin B12 in genomic stability of human cells. Mutat Res 475: 57-67.

40. Wang X, Thomas P, Xue J, Fenech M (2004) Folate deficiency induces aneuploidy in human lymphocytes in vitro-evidence using cytokinesisblocked cells and probes specific for chromosomes 17 and 21. Mutat Res 551: $167-180$

41. Andreassi MG, Botto N, Cocci F, Battaglia D, Antonioli E, et al. (2003) Methylenetetrahydrofolate reductase gene C677T polymorphism, homocysteine, vitamin B12, and DNA damage in coronary artery disease. Hum Genet 112: 171-177.

42. Meguid NA, Dardir AA, Khass M, Meguid NA, Dardir AA, et al. (2008) MTHFR genetic polymorphism as a risk factor in Egyptian mothers with Down syndrome children. Dis Markers 24: 19-26.

43. Coppedè F, Colognato R, Bonelli A, Astrea G, Bargagna S, et al. (2007) Polymorphisms in folate and homocysteine metabolizing genes and chromosome damage in mothers of Down syndrome children. Am J Med Genet A 143: 2006-2015.

44. Migliore L, Boni G, Bernardini R, Trippi F, Colognato R, et al. (2006) Susceptibility to chromosome malsegregation in lymphocytes of women who had a Down syndrome child in young age. Neurobiol Aging 27: 710-716. 